\title{
Smoking, drinking, and other life style factors and cognitive function in men in the Caerphilly cohort
}

\author{
P C Elwood, J E J Gallacher, Carol A Hopkinson, Janet Pickering, P Rabbitt, B Stollery, \\ Carol Brayne, Felicia A Huppert, A Bayer
}

\begin{abstract}
Study objectives-To examine the cognitive function in a large, ongoing cohort study of older men, and to identify associations with social and lifestyle factors.

Design-A cross sectional study of cognitive function was conducted within the Caerphilly Prospective Study of Heart Disease and stroke.

Setting-The Caerphilly Study was originally set up in 1979-83 when the men were 45-59 years of age. Extensive data are available on a wide range of lifestyle and other factors of possible relevance to cognitive decline. Associations between some of these and cognitive function are reported.
\end{abstract}

MRC Epidemiology Unit, Llandough Hospital, Penarth, South Glamorgan CF64 2XW

P C Elwood

J E J Gallacher

C A Hopkinson

J Pickering

University of Manchester, Age and

Cognitive

Performance,

Research Centre,

Manchester

P Rabbitt

Department of

Psychology, University

of Bristol

B Stollery

Department of Community Medicine, Department of Psychiatry, University of Cambridge

C Brayne

Department of

Psychiatry, University of Cambridge

F A Huppert

University

Department of

Geriatric Medicine,

Llandough Hospital,

Penarth, South

Glamorgan

A Bayer

Correspondence to:

Dr P C Elwood.

Accepted for publication 18 August 1998
Participants-A representative sample of 1870 men aged 55-69 years.

Main results-Age, social class, medication, and mood were found to be powerful determinants of performance. Self report data on the involvement of the men in leisure pursuits were examined by factor analysis. This indicated that the more intellectual leisure pursuits are the most strongly linked with performance. A measure of social contact showed a weak positive association with the test scores. Current cigarette smokers gave lower test cognitive function scores than either men who had never smoked, or ex-smokers. There was however no evidence of any gradient in function with the total lifetime consumption of tobacco. The disparity between these two data sets suggests that there had been prior selection of men who had originally started to smoke, but more particularly selection of those who later quit smoking. There was no significant association between alcohol consumption and cognitive function, though ex-drinkers had markedly lower test scores than either current drinkers or men who had never drunk alcohol. This seemed probably to be a consequence of an high prevalence of illness among the ex-drinkers.

Conclusions-Age and social class show strong associations with cognitive function. Leisure persuits and social contact are also both positively associated. Neither tobacco smoking nor the drinking of alcohol seem to be associated with cognitive function, though there is evidence suggestive of self selection of both men who had never smoked and ex-smokers. (F Epidemiol Community Health 1999;53:9-14)
The rising numbers of older people in the community has led to an increasing concern with cognitive decline and dementia, and this has stimulated an increasing interest in aetiological factors other than age. ${ }^{1-6}$ Holland and Rabbitt ${ }^{7}$ have pointed out that cognitive decline has three components: involutionary decline, which might be accepted as "natural" aging, secondly pathology, and thirdly, socioeconomic factors. None of these has yet been adequately characterised or measured, though Holland and Rabbitt judge the effect of socioeconomic factors to be powerful, and likely to play a major part in the determination of life's opportunities and histories. Jones et $a l^{8}$ support this view and claim that the direct effect of age on cognition is "substantially" reduced when social, lifestyle, and physiological variables are taken into account.

In the investigation of how lifestyle factors affect the maintenance of cognitive function an obvious starting point is to evaluate the associations with cognitive function and common everyday factors, such as leisure time activities, physical exercise, and contact from family and friends, in a representative population sample of "younger" elderly subjects. Because of marked disagreement in previous findings, the effects of smoking and drinking are of particular interest.

In this paper we investigate the association of cognitive performance with a variety of lifestyle factors, in particular, smoking, and drinking, within the Caerphilly Cohort, a large representive sample of older men.

\section{Methods}

The Caerphilly Study was set up in 1979-83, the aims being the study of lifestyle, dietary, biochemical, and haemostatic factors predictive of ischaemic heart disease. More recently, stroke has been added as an outcome. The study is described more fully elsewhere. ${ }^{9}{ }^{10}$ Every man included gave signed, informed consent at every phase of the work.

The men in the cohort have been reexamined at four to five year intervals, and in the second re-examinations, the men being 55-69 years, cognitive function was added to the investigations. Full details of the testing of each man are given elsewhere. ${ }^{11}$

Men were asked about a wide range of aspects of lifestyle and medical history, and current occupation, or most recent job was used as a basis for social class classification. Cigarette consumption was recorded, both in terms of each man's current habit, and in terms of an estimated lifetime consumption of 
tobacco. The usual alcohol intake was recorded, and a daily consumption over an average week estimated.

Medication, both prescribed and "over the counter" were recorded. Preliminary analyses showed that many drugs have an association with cognitive performance. Therefore one of us $(\mathrm{AB})$, together with a pharmacologist, grouped the drugs that the men in the cohort were taking, into: (1) those unlikely to have any effect on cognitive function; (2) those that may have some effect (such as, antimuscarinics, corticosteroids, digoxin), and (3) those likely to have an appreciable effect (such as antipsychotics, tricyclic antidepressants, phenytoin). This grouping was used as a basis for a process of statistical adjustment to allow for possible confounding effects by medication on other relations.

Using a questionnaire that listed 18 items, subjects were asked to indicate on a five point scale the frequency with which each engaged in a range of leisure pursuits. These were examined first by factor analysis in an attempt to reduce the activities and interests into a small number of separate, uncorrelated items. Relations between these factors and cognitive performance were then examined.

An estimate of the social contact received by each man was obtained from a questionnaire, which asked the average number of persons, family and friends, with whom there was meaningful daily contact.

THE TESTS OF COGNITIVE FUNCTION

Shortly after the clinic attendance, each man was seen at home by one of us $(\mathrm{CH})$. Cognitive function tests were completed by the men, alone, in a quiet room, and they were asked not to smoke during testing. The order of the tests, and the method of application was rigidly standardised. A laptop computer was used for some of the tests. This had a very simple keyboard in place of the usual alpha-numeric keys, and a gas-plasma screen to ensure that each signal disappeared as soon as it had been answered.

Cognitive function was measured with several instruments and these were always applied in precisely the same way and in the same order.

The $\mathrm{AH} 4^{12}$ comprises a series of 65 items of increasing difficulty alternating between verbal and mathematical reasoning items. These items were presented using a laptop computer and the score used is the total number of correct answers made within a standard limit of 10 minutes.

The Cambridge Cognitive Examination $(\mathrm{CAMCOG})^{1314}$ and Mini-Mental State Examination (MMSE) $)^{15}$ were included as tests of cognitive loss. Both are widely used in clinical practice, the CAMCOG being the more precise. They assess a range of functions and skills including language, praxis, perception, memory, attention, and orientation.

In the Choice Reaction Time (CRT) the subject is presented with a stimulus in one of four boxes on the computer screen and is instructed to press the appropriate button on a special four button keyboard. A total of 160 stimuli, balanced for position and latency are presented. Responses under $100 \mathrm{~ms}$ were omitted as these indicate anticipation, rather than response. Responses over 30 s were also omitted as was the longest response if it was more than twice the duration of the next longest response as these were considered to have been influenced by distractions. In this report mean response time is derived from all acceptable responses, regardless of whether or not the response was correct.

In addition, a 30 question form of the General Health Questionnaire (GHQ) ${ }^{16}$ was administered to give an indication of the mood of each man at the time of testing. In the regression analyses that follow, the original score, with some grouping to allow for skew and unevenness in the distribution, is added to the models to allow for any confounding of the cognitive tests by mood. The GHQ is however of some interest as a determinant of performance itself.

STATISTICAL METHODS

The number of possible indices that could be derived from the tests of cognitive function is legion. We made a prior decision to use the following:

AH4: the total number of questions answered correctly within 10 minutes.

CAMCOG: the total score, with a maximum of 104 .

MMSE: the total score, with a maximum of 30.

CRT: the mean response time of all the responses.

The associations between these scores and a variety of lifestyle factors of possible relevance is examined and differences in scores between subgroups are adjusted as appropriate for the effects of differences in confounding factors, namely, social class, drug taking, and depression (GHQ score). Adjustment for confounding by age has been done throughout by individual year.

\section{Results}

The sample comprised 2154 men aged 55-69 years who were seen in the second reexamination in the Caerphilly cohort study. Of these, $1870(87 \%)$ agreed to cognitive testing. Results from men who had suffered a stroke, or had problems with the testing procedure were omitted, together with those where there had been an equipment failure during testing. Cognitive testing was successful and performance data are therefore available for 1685 men with the AH4, 1781 with the CAMCOG and MMSE, and 1649 with the CRT.

Table 1 displays the mean scores for each test within three age groups. As expected, there are very clear declining trends with increasing age. The data displayed in this table, as in all that follow, have been adjusted for the effects of other factors likely to confound the relations of interest: in this case, the possible confounding effects of social class, medication, and mood at the time of testing have been controlled for. 
Table 1 Cognitive function and age

\begin{tabular}{llllll}
\hline Age $(y)$ & $\begin{array}{c}\text { Men } \\
(n)\end{array}$ & AH4 & CAMCOG & MMSE & CRT \\
\hline $55-59$ & 591 & $27.5(10.8)$ & $91.5(5.8)$ & $27.0(2.1)$ & $874(224)$ \\
$60-64$ & 536 & $25.4(10.1)$ & $89.7(6.7)$ & $26.5(2.4)$ & $912(228)$ \\
65-69 & 501 & $23.5(9.9)$ & $88.0(7.3)$ & $25.9(2.5)$ & $988(279)$ \\
Age effect & & -0.465 & -0.348 & -0.105 & +11.7 \\
Probability of trend & & $<0.0005$ & $<0.0005$ & $<0.0005$ & $<0.0005$ \\
\hline
\end{tabular}

Cases who had had a stroke have been excluded in this, and in all subsequent tables.

*The "age effect" shown is the unstandardised regression coefficient of each test on age in years. The mean scores (SD) for the various tests are shown after adjustment for the effects of social class, drugs, and GHQ score at the time of testing.

Table 2 displays the relations between the tests and a number of possible confounding factors. Clearly social class has very strong relations with each test. After adjustment for the effects of age, medication, and mood at the time of testing (GHQ), the differences across the grouped classes (I+II and IV+V) is equivalent to just over one standard deviation for the AH4 (11.3) and the CAMCOG (6.0), over half a standard deviation for the MMSE (1.5), and just under half a standard deviation for the CRT (100 ms).

Associations of the various tests with mood at the time of testing are strong, even after allowing for the effects of the confounding factors, age, social class, and medication (table 2) being just under half of one SD for the $\mathrm{AH} 4$, rather less for the CAMCOG and MMSE, and about one quarter of a SD for the CRT. Mood at the time of testing is clearly a most important factor.

There are a few important associations with medication after the effects of confounding factors have been allowed for (table 2). The score in men who were taking drugs that had been judged by the geriatrician and the pharmacologist likely to have definite effects on performance have a mean score for the $\mathrm{AH} 4$ (24.4), which is much lower than that of men receiving either no medication, or receiving drugs judged unlikely to affect cognition (26.3 and 27.0). These differences are equivalent to around $20 \%$ of the standard deviation for the test. The performance of men taking drugs that had been judged only to have "possible" effects

Table 2 Cognitive function and various factors

\begin{tabular}{|c|c|c|c|c|c|}
\hline & $\begin{array}{c}\text { Men } \\
(n)\end{array}$ & $\mathrm{AH} 4$ & CAMCOG & MMSE & $C R T$ \\
\hline \multicolumn{6}{|l|}{ Social class } \\
\hline $\mathrm{I}+\mathrm{II}$ & 411 & $32.4(9.9)$ & $93.1(5.0)$ & $27.4(1.9)$ & $886(221)$ \\
\hline III non-manual & 146 & $28.9(8.9)$ & $92.1(4.6)$ & $27.4(1.6)$ & $865(117)$ \\
\hline III manual & 753 & $22.8(9.0)$ & $88.7(6.4)$ & $26.1(2.4)$ & $922(240)$ \\
\hline $\mathrm{IV}+\mathrm{V}$ & 318 & $21.1(9.3)$ & $87.1(7.9)$ & $25.9(2.6)$ & $998(302)$ \\
\hline Probability of trend & & $<0.0005$ & $<0.0005$ & $<0.0005$ & $<0.0005$ \\
\hline \multicolumn{6}{|l|}{ GHQ (see text) } \\
\hline 0 & 688 & $27.0(10.4)$ & $90.8(6.2)$ & $26.7(2.3)$ & $906(239)$ \\
\hline $1-7$ & 715 & $25.010 .2)$ & $89.5(6.7)$ & $26.5(2.4)$ & $922(239)$ \\
\hline $8+$ & 225 & $23.0(10.5)$ & $87.9(7.5)$ & $26.0(2.5)$ & $975(294)$ \\
\hline Probability of trend & & $<0.0005$ & $<0.0005$ & $<0.0005$ & $<0.0005$ \\
\hline \multicolumn{6}{|l|}{ Medication ${ }^{\star}$ (see text) } \\
\hline Men on no drug & 417 & $26.3(11.0)$ & $89.5(6.9)$ & $26.5(2.3)$ & $905(236)$ \\
\hline \multicolumn{6}{|l|}{ Men on drugs likely } \\
\hline to have no effect & 270 & $27.0(10.5)$ & $90.7(6.2)$ & $26.7(2.2)$ & $896(226)$ \\
\hline Probability & & NS & $<0.05$ & NS & NS \\
\hline possible effects & 436 & $25.4(10.2)$ & $90.3(6.5)$ & $26.7(2.3)$ & $922(229)$ \\
\hline Probability & & NS & NS & NS & NS \\
\hline probable effects & 505 & $24.4(9.8)$ & $89.2(6.8)$ & $26.2(2.5)$ & $949(278)$ \\
\hline Probability & & $<0.005$ & NS & NS & $<0.05$ \\
\hline
\end{tabular}

${ }^{\star}$ Medications have been grouped by their likely effect on cognitive function (see text). The significance levels indicated are for differences from the base group: men on no drug.

The mean scores (SD) have been adjusted for the effects of age, and also, as appropriate, for social class, GHQ score at the time of testing, and the effects of medication.
KEY POINTS

- Leisure time activities show a positive association with cognitive function, especially the more intellectual persuits.

- Cigarette smoking shows no association, but there is evidence that the more able smokers quit and became ex-smokers.

- Light and moderate drinking shows no association.

on cognition is intermediate for the $\mathrm{AH} 4$ and the CRT. Despite the fact that only a few of the relations with medication are significant, the regression models that follow later have all included medication at four levels, as defined earlier.

The factor analysis of the 18 leisure time pursuits by each man led to the identification of four factors that were judged to be useful in that they each had eigen values greater than one $(2.8 .1 .9,1.3$, and 1.1 respectively in what follows). These were interpreted as "social" (this included attendance at dances and other social events, being a spectator at sports, visiting a public house or club, playing darts, snooker etc), "cultural" (participation in music or drama, visiting concerts, theatre, cinema or church, doing community or voluntary work, etc), "intellectual" (attending lectures, classes, libraries, museums, playing desk games of skill, involvement in creative arts, etc), and "physical" (gardening, walking jogging, participation in ball games, doing household jobs, etc). Varimax rotation with Kaiser normalisation was used to maximise the variance of the factor loading, but this had no impact on the explanatory power of the factors.

The associations of these leisure "factors" with the cognitive function test results were then examined. Table 3 displays regression coefficients that have been standardised to represent change in cognitive performance in terms of SDs of the cognitive tests, so that direct comparisons can be made between the tests, so they can all be compared. Clearly the strongest relations are those between the cognitive tests and the more "intellectual" activities, and the single most marked association is between these activities and the $\mathrm{AH} 4$, the test that is most closely related to reasoning ability. Perhaps surprisingly, the more physical leisure pursuits show the next strongest relations, while the factor for social pursuits shows no association with cognitive performance.

From another questionnaire applied to each man we have an estimate of the social contact each man claimed to receive, in terms of the average number of persons with whom he had meaningful contact in an average week. Associations with cognitive function are weak (table 3), and are best shown by the CAMCOG and the MMSE, the questionnaires that best detect dementia.

Table 4 summarises the effects of smoking on cognitive function. Men who were current smokers at the time of testing gave mean scores on the AH4 (23.9) and the CAMCOG (88.6), which were lower than in men who had never 
Table 3 Cognitive function, leisure pursuits, and social contacts

\begin{tabular}{|c|c|c|c|c|c|}
\hline & $\begin{array}{l}\text { Men } \\
(n)\end{array}$ & AH4 & CAMCOG & $M M S E$ & $C R T$ \\
\hline \multicolumn{6}{|c|}{ "Leisure pursuit" factors (see text) } \\
\hline intellectual & 1232 & 0.198 & 0.164 & 0.082 & -0.117 \\
\hline Probability & & $<0.0005$ & $<0.0005$ & $<0.005$ & $<0.0005$ \\
\hline cultural & 1232 & 0.043 & 0.056 & 0.055 & -0.003 \\
\hline Probability & & NS & $<0.05$ & $<0.05$ & NS \\
\hline social & 1232 & 0.004 & 0.031 & 0.022 & -0.061 \\
\hline Probability & & NS & NS & NS & $<0.05$ \\
\hline physical & 1232 & 0.069 & 0.100 & 0.116 & -0.011 \\
\hline Probability & & $<0.05$ & $<0.0005$ & $<0.0005$ & NS \\
\hline \multicolumn{6}{|l|}{ Social contacts (see text) } \\
\hline $0-12$ & 573 & $25.6(10.3)$ & $89.5(7.1)$ & $26.3(2.6)$ & $936(271)$ \\
\hline $13-16$ & 528 & $24.9(10.7)$ & $89.8(6.5)$ & $26.5(2.3)$ & $918(212)$ \\
\hline $17+$ & 467 & $26.6(10.4)$ & $90.4(6.5)$ & $26.7(2.3)$ & $904(248)$ \\
\hline Probability of trend & & NS & $<0.05$ & $<0.05$ & $<0.05$ \\
\hline
\end{tabular}

For "leisure pursuits" the figures shown are standardised regression coefficients for the factors identified in the factor analysis described in the text. The coefficients have been adjusted for age, social class, and GHQ and medication. For social contacts, mean scores (SD) have been adjusted for the effects of age, social class, and GHQ and medication.

Table 4 Cognitive function and smoking

\begin{tabular}{lcllll}
\hline Smoking & $\begin{array}{c}\text { Men } \\
(n)\end{array}$ & AH4 & CAMCOG & MMSE & CRT \\
\hline Current status & & & & & \\
$\quad$ never smoked & 290 & $26.0(11.0)$ & $90.2(6.2)$ & $26.5(2.3)$ & $929(224)$ \\
$\quad$ ex-smokers & 785 & $26.3(10.2)$ & $91.0(6.6)$ & $26.6(2.4)$ & $906(244)$ \\
$\quad \begin{array}{l}\text { current cigarette } \\
\text { pipe/cigar }\end{array}$ & 436 & $23.9^{\star}(10.1)$ & $88.6+(7.0)$ & $26.2(2.4)$ & $939(270)$ \\
Life time cigarette consumption & 110 & $25.9(10.0)$ & $91.0(6.3)$ & $26.7(2.2)$ & $941(216)$ \\
$\quad$ under 183K & 548 & $25.6(10.1)$ & $89.9(6.5)$ & $26.5(2.2)$ & $915(249)$ \\
$\quad$ 183K-364K & 537 & $25.7(10.4)$ & $89.5(7.0)$ & $26.4(2.5)$ & $927(265)$ \\
$365 \mathrm{~K}+$ & 204 & $25.2(10.2)$ & $89.9(6.6)$ & $26.6(2.4)$ & $906(223)$ \\
\hline
\end{tabular}

Significance levels are for differences from the base groups: men who never smoked. ${ }^{\star} \mathrm{p}<0.005$ $\mathrm{tp}<0.0005$.

Mean scores have been adjusted for the effects of age, social class, drugs, and GHQ.

smoked, by 2.1 and 1.6 respectively, (equivalent to $20 \%$ and $24 \%$ of a SD). The mean score for the CRT shows no obvious difference between smokers and non-smokers. On the other hand, ex-smokers and pipe and cigar smokers show no significant differences in any function from men who had never smoked.

The possibility that the effect of smoking is more marked in less able men was then considered. The analysis summarised in table 4 was repeated after dividing the men into the half with the highest cognitive function scores, and the half with the lowest scores. The scores for all the tests were homogeneous.

A further way to examine the effect of smoking is to look for a gradient in the scores against total lifetime cigarette consumption. This last was estimated from detailed questions about smoking history throughout life. The analysis makes allowance for differences in age, and for the possible confounding effects of social class, medication and mood. No test gives evidence

Table 5 Cognitive function and alcohol consumption

\begin{tabular}{llllll}
\hline $\begin{array}{l}\text { Usual alcohol } \\
\text { consumption }\end{array}$ & $\begin{array}{l}\text { Men } \\
(n)\end{array}$ & AH4 & CAMCOG & MMSE & CRT \\
\hline Life time abstainers & 40 & $24.9(10.7)$ & $89.1(5.7)$ & $26.2(2.3)$ & $980(296)$ \\
Drinkers at any time & 1580 & $25.6(10.5)$ & $89.8(6.7)$ & $26.5(2.3)$ & $920(244)$ \\
All current drinkers & 1499 & $25.8(10.4)$ & $90.1(6.5)$ & $26.5(2.3)$ & $916(239)$ \\
$\quad$ lowest 1/4 drinkers & 419 & 25.9 & 89.9 & 26.4 & 923 \\
next 1/4 & 390 & 25.7 & 89.9 & 26.5 & 913 \\
next 1/4 & 310 & 25.9 & 89.9 & 26.5 & 916 \\
next 1/4 & 380 & 25.6 & 90.2 & 26.6 & 911 \\
Ex-drinkers & 81 & $22.3 \dagger(10.8)$ & $87.3 \ddagger(8.5)$ & $26.0^{\star}(2.8)$ & $990^{\star}(307)$ \\
\hline
\end{tabular}

Significance levels are for differences from the lowest group of drinkers. ${ }^{\star} \mathrm{p}<0.05 ; \mathrm{tp}<0.005$; $\neq \mathrm{p}<0.0005$.

Mean scores have been adjusted for the effects of age, social class, drugs, and GHQ. of a trend in cognitive function with lifetime cigarette consumption (table 4 ).

Table 5 summarises the association between usual alcohol consumption and cognitive function. There is no evidence of any significant association between the amount drunk and any of the tests, and this conclusion holds even for the heaviest drinkers. Ex-drinkers, however, show scores on all the tests that are very markedly lower than those of both the current drinkers and lifetime abstainers. Clearly, men give up alcohol for a variety of reasons and some of these reasons may be relevant to cognitive performance. The records for the 81 men who had quit drinking were therefore examined in detail. A considerable proportion of the men had morbid conditions: $46 \%$ of them had evidence of ischaemic heart diseases compared with $36 \%$ in the total cohort, and a considerably higher proportion were taking medication ( $93 \%$ of the ex-drinkers, compared with $75 \%$ in the total cohort were taking some form of medication).

\section{Discussion}

The main strength of the Caerphilly Cohort Study is that it is based on a representative population sample. Measures have been made, many repeatedly, of lifestyle, dietary, lipid, haemostatic, platelet, and other factors of possible relevance to ischaemic heart disease and stroke. ${ }^{17-19}$ It is our intention to examine the relevance of these factors, and of cardiovascular disease and diabetes to cognitive function. A randomised controlled trial of low dose aspirin and cognitive decline has also been set up within the cohort. In this first report we focus on associations with a number of lifestyle factors on cognitive function.

The test scores in these men are of interest as they are representative of a population of free living older men. Some selection was inevitable, in that $13 \%$ of the original cohort refused to be tested, and the data from a further $9 \%$ were excluded for technical reasons. In common with other studies, the results for all the tests show a negative skew indicating that there is a small excess proportion of men with scores likely to indicate dementia. Applying criteria commonly used in clinical practice for significant deficit, 179 men (8\%) scored below 80 on the CAMCOG and $128(6 \%)$ below 22 on the MMSE.

All the tests seem to be sensitive to mood at the time of examination, as judged by the GHQ. The effect is not trivial, the difference between the mean scores in the men likely to be depressed (GHQ scores of 8 or greater) and those with no evidence of depression (GHQ scores of 1 or less) being about $40 \%$ of a SD for both the AH4 and the CAMCOG, and about $26 \%$ of a SD for the CRT. The issue of causality of course arises and cannot be settled by cross sectional data. There is a further complication however in our data in that the results of the CAMCOG indicate a more marked decline in cognitive function with age in the men who seem to be depressed, than in men not depressed. The tests other than the CAMCOG showed no such interaction with mood. Rabbitt 
et $a l^{20}$ examined this same issue in a much larger sample of volunteers and concluded that age, of itself, is unlikely to increase vulnerability to the effects of depression on cognitive performance. Apart from the CAMCOG results, our data concur with this conclusion.

The effect of social class is very marked (table 2) and the trend across the full range of social classes I to $\mathrm{V}$ is consistent and even more marked. The size of this for the MMSE (1.5 in table 2) is very closely similar to that attributed to education (namely 1.7) in the Rotterdam study. ${ }^{5}$ Huppert et $a l^{14}$ found that in a population sample in Cambridge, education and social class exerted a significant and independent effect upon performance. Our population sample was however drawn from a former coal mining area where there had been relatively little opportunity for higher education in the 1920-30s and so social class and education are likely to be highly confounded. Elsewhere, however, we present results for both social class and level of educational achievement. ${ }^{11}$

The evidence on medication and cognitive function that we present in table 2, is confounded with the effects of the diseases for which the drugs were prescribed. This is unavoidable in an observational population study. However, the only use we make of medication in this report is to allow for the confounding effects of drugs on other relations. In a later publication we will examine the relations more closely.

The significant relations we describe with leisure pursuits are to be expected (table 3). The men in our cohort were comparatively young when tested, and so it is not surprising that the clearest relations are shown with the more intellectual component of leisure activities. On the other hand, it is difficult to explain the discrepancy between the absence of any significant relations with the social factor derived from the leisure pursuits, and the significant associations with the independent measure of social contact. These two indices seem however to be measuring rather different things as the correlation between them is low $(r$ $=0.38 ; \mathrm{p}<0.001$ ).

There are two possible effects of cigarette smoking on performance: acute and chronic. We examined only the second, and have found little evidence of any important effect. Although the men who admitted to cigarette smoking at the time of testing had scores that were lower than those in the men who did not smoke cigarettes, there is no evidence of a gradient with the estimated lifetime consumption of cigarettes (table 4).

The literature seems to give no consistent evidence of smoking on function. Berkman et $a l^{21}$ found that 1192 "high functioning" subjects smoked less cigarettes than 162 medium and low functioning subjects. Launer et $a l^{6}$ reported that, compared with subjects who had never smoked, current smokers made 20\% more errors on the MMSE, and Ferrucci et a ${ }^{22}$ also report a significant effect of smoking. In other studies, however, there is said to have been no association with smoking, ${ }^{23}$ or no modification of the associations with cognitive function when smoking was added to the model. ${ }^{24}$ On the other hand, Dobbs et $a l^{25}$ found cigarette smoking to be associated with increased efficiency in a reaction time test, both in 103 subjects with Parkinsonism and in 144 without. Evidence from the Rotterdam cohort study ${ }^{5}$ is consistent with this last in that smoking was found to be less common in subjects with dementia (relative risk, compared with subjects without dementia: 0.35), thus raising the possibility that smoking may protect against cognitive decline. The effects of smoking on cognitive performance may however be complex. While nicotine has both acute and chronic beneficial effects on performance, ${ }^{26} 27$ other effects of smoking, and in particular on the vascular and haemostatic systems are certainly deleterious.

On the other hand, our data would support the hypothesis that some of the differences in performance between groups of men defined by their smoking habit may be a consequence of self selection out of the smoking groups. In particular, smokers with higher cognitive function scores seem to be more likely to quit and transfer into the ex-smoking group.

Relations between drinking and cognition are of particular interest, and a number of hypotheses have been defined. ${ }^{28}$ There are undoubted harmful effects in chronic alcoholics, but the proportion of these in a community based study such as ours is too small to merit separate consideration. Our data relate more to the effects of "social" drinking. Two hypotheses have been proposed: firstly, that there is a continuum of permanent effects positively related to the usual alcohol intake and, secondly, that there is a "hang over" effect after each drink, with an eventual return to baseline function. Studies of cerebral blood flow would seem to support the former of these hypotheses, as a significant inverse relation has been reported between grey matter blood flow and the usual amount drunk. ${ }^{29}$ Other hypotheses arise from the assumption that personality and cognitive function determine the pattern of drinking and the amount drunk, and in one study such a relation was shown clearly in young adults who had intermittent episodes of immoderate drinking. ${ }^{30}$

The literature is confused on all these aspects, but this is probably a consequence of the small size of many of the previous studies and the selected nature of the subjects chosen for study. Although we have made every reasonable attempt to ensure that our sample of men is representative of the general population of older men, yet the heaviest drinkers are still likely to be under-represented as they are likely to be less cooperative in any community based study. It would however seem to be reasonable to conclude from our data that social drinking, which describes most of the drinking in our population sample, has little or no chronic affect on cognitive function. There is certainly no evidence in our data to support the conclusion drawn from the smaller Zutphen cohort that alcohol intake is protective against cognitive decline. ${ }^{6}$ 
The finding of a marked deficit in performance in the ex-drinkers in our sample is almost certainly a consequence of morbidity that had led to the cessation of drinking. Thus we find that a high proportion of these men were taking medication, and almost half had definite evidence of ischaemic heart disease. A similar result was reported in women by Ensrud et a ${ }^{11}$ who found that "former alcohol use" was a significant predictor of impaired function, while current alcohol use was not.

Another approach to the evaluation of smoking and drinking on cognitive function is to examine cerebral blood flow. Thus Rogers et $a l^{32}{ }^{33}$ found a negative and continuous relation between blood flow, and both smoking and drinking habit. While it could be that grey matter that has been impaired by smoking and/or drinking, will require less blood, further results by Rogers et $a l^{34}$ showed that the quitting of smoking was followed by an improvement in blood flow, suggesting a direct effect. Yet other work by this group showed a decreased vasodilator and vasoconstriction response in cerebral vessels in chronic cigarette smokers. ${ }^{34}$

Clearly, as this cohort ages, the changes in the pattern of associations between the different tests of cognitive function and their likely determinants will be of increasing interest.

We are grateful to Dr Michael Bialus who assisted in the coding of medications.

Funding: the field work described was entirely funded by MRC. The statistical work was done by Janet Pickering, funded by Mental Health Foundation.

1 Farmer ME, Kittner SJ, Abbott RD, et al. Longitudinally measured blood pressure, antihypertensive medication use, and cognitive performance:

2 Elias MF, Wolf PA, D'Agostino B, et al. Untreated blood pressure is inversely related to cognitive functioning: the Framingham study. Am f Epidemiol 1993;138:353-64.

3 Skoog I, Nilsson L, Palmertz B, et al. A population-based study of dementia in 85 year olds. $N$ Engl f Med 1993;328: $153-8$

4 Skoog I, Lernfelt B, Landahl S, et al. 15-year longtidunal study of blood pressure and dementia. Lancet 1996;347: 1141-5.

5 Breteler MMB, Claus JJ, Grobee DE, et al. Cardiovascular disease and distribution of cognitive function in elderly people: the Rotterdam study. BMF 1994;308:1604-8

people: the Rotterdam study. BMj 6 Launer LJ, Freskens EJM, Kalmjin S, et al. Smoking, drink-
6 . ing and thinking. The Zutphen Elderly Study. Am $\mathcal{f}$ Epidemiol 1996;143:219-27.

7 Holland CA, Rabbitt P. The course and causes of cognitive Holland CA, Rabbitt P. The course and causes of cognitive
change with advancing age. Reviews in Clinical Gerontology change with advar

8 Jones KJ, Albert MS, Duffy FH, et al. Modeling age using cognitive, psychosocial and physiological variables: the Boston normative aging study. Exp Aging Res 1991;17:22742.

9 Caerphilly and Speedwell Collaborative Group. Caerphilly and Speedwell collaborative heart disease studies. $\mathcal{F}$ Epidemiol Community Health 1984;38:259-62.
10 Stansfeld SA, Sharp DS, Gallacher JEJ, et al. A population survey of ischaemic heart disease and minor psychiatric survey of ischaemic heart disease and minor
disorder in men. Psychol Med 1992;22:939-49.

11 MRC Epidemiology Unit. Epidemiological studies of cardiovascular diseases: Progress report VII. Penarth: MRC Epidemiology Unit, 1991.

12 Heim AW. AH4 Group Test of General Intelligence ASE. Windsor:The NFER-Nelson Publishing Company, 1970.

13 Roth M, Huppert FA, Tym E, et al. CAMDEX: The Cambridge examination for mental disorders of the elderly. Cambridge: Cambridge University Press, 1988.

14 Huppert FA, Brayne C, Gill C, et al. CAMCOG - A concise neuropsychological test to assist dementia diagnosis: sociodemographic determinants in an elderly population sample. Br f Clin Psychol 1995;34:529-41.

15 Folstein MF, Folstein SE, McHugh PR. Mini-Mental State Examination. A practical method for grading the cognitive state of patients for the clinician. F Psychiatric Res 1975;12: 189-98.

16 Goldberg DP. The detection of psychiatric illness by questionnire. London: Oxford University Press, 1972.

17 Yarnell JWG, Baker IA, Sweetnam PM, et al. Fibrinogen, viscosity, and white blood cell count are major risk factors for ischemic heart disease. The Caerphilly and Speedwell for ischemic heart disease. The Caerphilly and Speedwell 836-44.

18 Fehily AM, Yarnell JWG, Sweetnam PM, et al. Diet and incident ischaemic heart disease: the Caerphilly Study. Br $\mathcal{F}$ Nutr 1993;69:303-14.

19 Yarnell JWG, Beswick AD, Sweetnam PM, et al. Endogenous sex hormones and ischemic heart disease in men. The Caerphilly Prospective Study. Arterioscler Thromb 1993;13:517-20.

20 Rabbitt P, Donlan C, Watson $\mathrm{P}$, et al. Unique and interactive effects of depression, age, socioeconomic advantage, and gender on cognitive performance of normal healthy older gender on cognitive performance of n
people. Psychol Aging 1995;10:307-13.

21 Berkman LF, Seeman TE, Albert M, et al. High, usual and impaired functioning in community-dwelling older men and women: findings from the MacArthur Foundation Research Network on Successful Aging. $f$ Clin Epidemiol 1993;46:1129-40.

22 Ferrucci L, Guaralnik JM, Salive ME, et al. Cognitive impairment and risk of stroke in the older population. $7 \mathrm{Am}$ Geriatr Soc 1996;44:237-41.

23 Gale CR, Martyn CN, Cooper C. Cognitive impairment and mortality in a cohort of elderly people. BMF 1996;312: 608-11.

24 Freskens EJM, Havekes LM, Kalmijn S, et al. Apolipoprotein e-allele and cognitive decline in elderly men. $B M \mathcal{F}$ 1994;309:1202-6.

25 Dobbs RJ, Bowes SG, Charlett A, et al. Hypothesis: the bradyphrenia of Parkinsonism is a nosological entity. Acta Neurol Scand 1993;87:255-61. [Published erratum appears in Acta Neurol Scand 1993;87:517].

26 Le Houezec J, Halliday R, Benowitz NL, et al. A low dose of subcutaneous nicotine improves information processing in non-smokers. Psychopharmacology 1994;114:628-34.

27 Arendash GW, Sanberg PR, Sengstock GJ. Nicotine enhances the learning and memory of aged rats. Pharmacol Biochem Behav 1995;52:517-23

28 Delin CR, Lee TH. Drinking and the brain: current evidence. Alcohol Alcoholism 1992;27:117-26.

29 Rogers RL, Meyer JS, Shaw TG, et al. Reductions in regional cerebral blood flow associated with chronic consumption of alcohol. F Am Geriatr Soc 1983;31:540-3.

30 Bates ME, Tracy JI. Cognitive functioning in young "social drinkers": is there impairment to detect? f Abnorm Psychol 1990;99:242-9.

31 Ensrud KE, Nevitt MC, Yunis C, et al. Correlates of impaired function in older women. F Am Geriatr Soc 1994; 42:481-9.

32 Rogers RL, Meyer JS, Shaw TG, et al. Cigarette smoking decreases cerebral blood flow suggesting increased risk for stroke. FAMA 1983;250:2796-800.

33 Rogers RL, Meyer JS, Judd BW, et al. Abstention from cigarette smoking improves cerebral perfusion among elderly chronic smokers. $\mathscr{F} A M A$ 1985;253:2970-4.

34 Rogers RL, Meyer JS, Shaw TG, et al. The effects of chronic cigarette smoking on cerebrovascular responsiveness to 5 per cent $\mathrm{CO}_{2}$ and 100 per cent $\mathrm{O}_{2}$ inhalation. $7 \mathrm{Am}$ Geriatr Soc 1984;32:415-20. 